\title{
On the proportionality of EU spatial ex ante coexistence regulations
}

\author{
Matty Demont ${ }^{\mathrm{a}, \mathrm{b} 1}$, Koen Dillen ${ }^{\mathrm{b}}$, Wim Daems ${ }^{\mathrm{b}}$, \\ Christophe Sausse ${ }^{\mathrm{c}}$, Eric Tollens ${ }^{\mathrm{b}}$ and Erik Mathijs ${ }^{\mathrm{b}}$ \\ ${ }^{a}$ Africa Rice Center (WARDA), B.P. 96, Saint-Louis, Senegal \\ ${ }^{\mathrm{b}}$ Agricultural and Food Economics Section, Department of Earth and Environmental Sciences, \\ Katholieke Universiteit Leuven, \\ Celestijnenlaan 200E bus 2411, B-3001 Leuven, Belgium \\ ${ }^{\mathrm{c}}$ Centre Technique Interprofessionel des Oléagineux Métropolitains (CETIOM), \\ Centre de Grignon B.P. 4, 78850 Thiverval Grignon, France
}

\begin{abstract}
The EU is currently struggling to implement coherent coexistence regulations on genetically modified (GM) and non-GM crops in all member states. While it stresses that any approach needs to be "proportionate to the aim of achieving coexistence", very few studies have actually attempted to assess whether the proposed spatial ex ante coexistence regulations (SEACERs) satisfy this proportionality condition. In this article, we propose a spatial framework based on an existing landscape and introduce the concept of shadow factor as a measure for the opportunity costs induced by SEACERs. Our empirical findings led us to advance the proposition that flexible SEACERs based on pollen barriers are more likely to respect the proportionality condition than rigid SEACERs based on isolation distances. Particularly in early adoption stages, imposing rigid SEACERs may substantially slow down GM crop adoption. Our findings argue for incorporating a certain degree of flexibility into SEACERs by advising pollen barrier agreements between farmers rather than imposing rigid isolation distances on GM farmers. The empirical questions of proportionality and flexibility have been largely ignored in the literature on coexistence and provide timely information for EU policy makers.
\end{abstract}

Keywords: biotechnology; policy analysis; opportunity costs; GIS; shadow factor

JEL classifications: C88, D23, O33, Q16, Q18

\section{Acknowledgements}

The financial support of the European Commission's 6th Framework Programme SIGMEA project (Sustainable Introduction of Genetically Modified organisms into European Agriculture) is gratefully acknowledged. We are grateful to Antoine Messéan, Jeremy Sweet, Christian Tritten, Yann Devos and Olivier Sanvido for their outstanding research support. In particular, we would like to acknowledge Antoine Messéan who initially encouraged us to analyze the concept of regulatory rigidity, which eventually led us to introduce the concept of the domino-effect (Demont et al., 2008b). We also have a great intellectual debt to an anonymous reviewer who encouraged us to go deeper in the theoretical construction of our model, which eventually led us to introduce the concept of shadow factor. We finally would like to thank a second anonymous reviewer and the editor for their constructive comments that greatly improved this manuscript. The authors assume full responsibility for any remaining shortcomings.

\footnotetext{
${ }^{1}$ Corresponding author. Tel.: +221-9626493; fax: +221-9626491.

E-mail address: m.demont@cgiar.org (M. Demont).
} 


\section{Introduction}

The European Union (EU) is currently struggling to implement coherent coexistence regulations on genetically modified (GM) and non-GM crops in all member states. According to the European Commission’s (EC) guidelines, “Coexistence refers to the ability of farmers to make a practical choice between conventional, organic and GM crop production, in compliance with the legal obligations for labeling and/or purity standards. The adventitious presence of GMOs [genetically modified organisms] above the tolerance threshold set out in Community legislation triggers the need for a crop that was intended to be a non-GMO crop, to be labeled as containing GMOs. This could cause a loss of income, due to a lower market price of the crop or difficulties in selling it. [...] Coexistence is, therefore, concerned with the potential economic impact of the admixture of GM and non-GM crops [...]” (EC, 2003). Since the publication of these guidelines, some member states have developed, and others are still developing, a diversity of ex ante regulations and ex post liability rules on the coexistence of GM and non-GM crops (EC, 2006).

In this article, our attention is drawn to the first group of ex ante regulations, and more specifically to spatial ex ante coexistence regulations (SEACERs). Our concern is that some of the proposed SEACERs may impose a burden on GM crop production. The European Commission has clearly emphasized the proportionality condition of SEACERs in a Communication to the Council and the European Parliament: “[...] coexistence measures should not go beyond what is necessary in order to ensure that adventitious traces of GMOs stay below the labelling threshold [...] in order to avoid any unnecessary burden for the operators concerned. While some member states have taken this advice into account, others have decided to propose or adopt measures that aim to reduce adventitious presence of GMOs below this level. In some cases, proposed measures, such as isolation distances between GM and non-GM fields, appear to entail greater efforts for GM crop growers than necessary, 
which raises questions about the proportionality of certain measures. [...] While the Commission recognizes the legitimate right to regulate the cultivation of GM crops in order to achieve coexistence, it stresses that any approach needs to be proportionate to the aim of achieving coexistence” (EC, 2006, p. 6).

The scientific and regulatory community mainly focused its attention on the technical nature of the issue, more specifically on the feasibility of the proposed SEACERs. A first school of thought examines the feasibility of keeping the adventitious presence of GM material in non-GM products below established tolerance thresholds (Ceddia et al., 2007; Damgaard and Kjellsson, 2005; Devos et al., 2005; Devos et al., 2004; Eastham and Sweet, 2002; Hoyle and Cresswell, 2007; Hüsken and Dietz-Pfeilstetter, 2007; Messéan et al., 2006; Sanvido et al., 2008; Van De Wiel and Lotz, 2006).

A second school of thought assesses the feasibility of implementing alternative SEACERs in a spatial environment. Perry et al. (2002) use a stylized square agricultural landscape to assess the feasibility of GM crop allocation under varying levels of SAECERs. They conclude that stringent SAECERs combined with an increase in adoption of organic cultivation restricts the cultivation of GM crops within the landscape, in some cases even hampering the coexistence of both production systems. Dolezel et al. (2005) confirm these findings by estimating the area lost for non-GM crop cultivation due to SAECERs in three Austrian regions. Moreover, this case study concludes that in landscapes with a high planting density of maize and small fields, spatial feasibility is negatively correlated to increases in the stringency of SAECERs and GM crop adoption. Sanvido et al. (2008) examine the feasibility of SAECERs under spatial constraints at two levels. At the aggregate level, national statistics are used to assess whether the available arable land in Swiss communes is large enough to enable isolating an assumed area allocated to GM maize. This approach is complemented by a Geographic Information System (GIS) analysis at the field level. The authors demonstrate 
that both the planting density as well as the distances between maize fields can strongly differ within the communes and hamper coexistence, despite the feasibility to comply with SAECERs at the aggregate level. Devos et al. (2007), using a combination of GIS data and Monte Carlo simulations, investigate how these spatial arrangements influence the feasibility of implementing SAECERs. Their results show that clustering may be an effective strategy to facilitate the coexistence of production systems. Therefore, Devos et al. (2008b) propose the theoretical solution of pooling arable land to increase the feasibility of SAECERs in the landscape. However, besides agronomical problems such as the promotion of monoculture, clustering also creates significant transaction costs. Furtan et al. (2007) assess the economic and institutional feasibility of such coordination through the case of private organic clubs in Canada. Although institutional settings differ between Canada and the EU, the results offer some insight in the dynamics of economic and institutional feasibility of SEACERs. If the size of the cluster decreases or SAECERs become more stringent, the costs of the private clubs increase. Messéan et al. (2006) use a GIS analysis to assess the influence of alternative SAECERs on farm level costs but do not provide any information on their economic feasibility and the impact of spatial patterns. Munro (2008) investigates spatial feasibility of SEACERs within an economic environment. Within the spatial restriction of a stylized rectangular agricultural landscape, he stresses the importance of appropriate policy options as efficient outcomes will not be achieved in an unregulated market. The feasibility of SAECERs depends mainly on the size of the barrier which must be maintained in order to avoid cross-fertilization. However, as the model is built on a simplified spatial economy, it does not take into account the geographical influence of landscape, land fragmentation, and field configuration on the spatial impact of GM crops. Ceddia et al. (2009) attempt to overcome the constraint of a stylized agricultural landscape through the incorporation of a general aggregation index, developed by He et al. (2000), in their model. Using this model, 
they assess the biological efficiency of different policy variables including SAECERs. However some of the proposed policies would not be feasible from an economic point of view as they would generate excessive costs for farmers. Moreover, the aggregation index does not account for the actual shape of agricultural plots.

This literature review shows that the interaction between SEACERs and the spatial configuration of the landscape is still poorly understood. Demont et al. (2008b) analyze this interaction and illustrate that spatial feasibility of SEACERs can be significantly reduced in densely planted areas if they trigger a domino-effect of non-GM crop planting decisions. However, it could be useful if this interaction could be summarized in a single measure. Moreover, the question whether the SEACERs currently proposed by the EC satisfy the proportionality condition has received limited attention in the literature (Demont et al., 2008b; Demont and Devos, 2008). Therefore, in this paper we develop a measure for assessing the spatial impact of SEACERs on the coexistence of a theoretical GM crop with its non-GM counterpart based on a real geographical dataset and analyze whether the proportionality condition is satisfied. The article is organized as follows. After this introduction, in Section 2 we introduce our new concept and describe our spatial modeling framework. In Section 3 we describe our spatial dataset and in Section 4 we report the results generated by the framework under a set of alternative scenarios. Section 5 critically discusses the results and Section 6 finally concludes. 


\section{Spatial modeling framework}

\section{Shadow factor}

SEACERs generally incorporate spatial isolation measures such as minimal distance requirements between GM and non-GM crops. They typically follow the newcomer principle in that they intend to protect conventional non-GM crops from the externalities caused by newcomers, i.e. new GM varieties of the same crop species (EC, 2003). Visually, we could interpret SEACERs as creating protective halos around non-GM crops in a landscape. Where a halo overlaps with a field where a GM crop is intended to be planted, a shadow is created on the field. Complying with SEACERs implies that shadows are exempt from GM crop planting of a particular crop species. Shadows induce opportunity costs as they constrain farmers' planting options. According to the newcomer principle, any costs for implementing coexistence measures are to be financially borne by GM crop farmers. Costs are not limited to opportunity costs; they also include operational and transaction costs. However, for the sake of parsimony our spatial analysis does only take into account opportunity costs as the latter are directly related to the spatial configuration of a landscape. Farmers intending to plant GM crops will weigh the costs of implementing coexistence measures against the benefits of planting GM crops (the so-called GM rents, see below). In other words, they will check whether the costs can be amortized over the remaining area they intend to plant with GM crops.

To summarize this trade-off, we define the shadow factor as the ratio of the total area of the shadow induced by SEACERs to the remaining total area planted with the GM crop assuming perfect compliance with SEACERs. The shadow factor is a measure for the opportunity costs borne by GM crop farmers per planted hectare of the GM crop as a result of complying with SEACERs. The nominator of the shadow factor measures the total area that needs to be converted to the second-best alternative crop, which can be a non-GM variety of 
the same crop species or another crop. The denominator relates the opportunity costs to the object to be regulated through SEACERs, i.e. the GM crop planting intentions. A shadow factor of one, for example, implies that the shadow induced by SEACERs covers half of the GM area, such that the opportunity costs borne by GM farmers on one unit of shadow need to be amortized over one unit of GM crops. The shadow factor can be used to assess the impact of alternative SEACERs in different landscapes under given market conditions as it summarizes the interaction between SEACERs and the spatial configuration of the landscape. In order to gain insight in the concept of shadow factor, in the remainder of the paper we simulate a set of alternative planting and adoption scenarios of a theoretical GM crop in a real landscape in Central France, subject to a continuum of distance requirements.

\section{Constrained randomization procedure (CRP) and ArcView ${ }^{\circledR}$ modeling}

Farmers plant GM crops in order to capture GM rents: increases in productivity and efficacy, reductions in production costs, and non-pecuniary benefits, such as increases in management flexibility (Breustedt et al., 2008; Demont et al., 2008a; Demont et al., 2007; Demont and Tollens, 2004; Demont et al., 2004; Gómez-Barbero et al., 2008; Marra and Piggott, 2006). However, in a given landscape the GM rents captured by farmers are heterogeneous, as farmers operate under heterogeneous conditions with respect to land quality, pest pressure, managerial expertise, education and market access. As a result, adoption of GM crops is often incomplete and GM crops coexist with non-GM counterparts in the landscape (Demont et al., 2008a; Dillen et al., 2008; Lapan and Moschini, 2004; Oehmke and Wolf, 2004; Weaver, 2004). Data on spatial heterogeneity that are precise and detailed enough to enable predicting adoption and planting patterns are generally rare. Therefore, in this paper we start from a set of plausible planting patterns, which are assumed to be the result of unobserved spatial heterogeneity in the landscape. In order to avoid imposing any pre-defined pattern of 
heterogeneity, we randomly allocate GM and non-GM traits among a randomly selected cropping pattern and repeat the process $n$ times through a Monte Carlo simulation so as to increase coverage of potential planting scenarios and reduce the standard error of the outcomes of the spatial analysis.

We develop a constrained randomization procedure (CRP) for ArcView ${ }^{\circledR}$ 3.2a to allocate a theoretical crop and its GM counterpart in the landscape, subject to two pre-defined planting conditions, i.e. planting density and GM adoption rate. GIS datasets are programmed in ArcView ${ }^{\circledR}$ through shape files, data structures developed by ESRI. Shape files are composed of spatial (feature geometry and index coordinates) and attribute information files. We add 'crop' and 'trait' attribute columns to the attribute information file and randomly select the crop (analyzed crop or other crop) and trait (GM or non-GM) in Microsoft Excel ${ }^{\circledR}$ 2007 by setting the likelihood of the random function equal to the planting density and the adoption rate. We run the CRP until we find 10 allocations which satisfy the planting constraints with a precision of $1 \% .{ }^{1}$ Each CRP run generates a new attribute information file, which is combined with the existing spatial files into a new ArcView ${ }^{\circledR}$ model.

For each ArcView ${ }^{\circledR}$ model, we add two layers ('themes'), i.e. a layer of 'non-GM polygons' and a layer of 'GM polygons'. Next, we create 10 layers of concentric buffers of increasing size $(10 \mathrm{~m}, 20 \mathrm{~m}, \ldots, 100 \mathrm{~m})$ as multiple rings around all non-GM polygons and dissolve the barriers between buffers of equal size. Next, we use the GeoProcessing Wizard to intersect the 10 buffer layers with the GM polygons. The 10 resulting intersection layers can be interpreted as the shadows casted on GM fields by imposing $10 \mathrm{~m}, 20 \mathrm{~m}, \ldots, 100 \mathrm{~m}$ distance requirements between GM and non-GM fields. The attribute information files of the layers finally enable calculating the shadow areas and shadow factors for all GM polygons and for the entire landscape under alternative distance requirements. 


\section{Data}

We borrow a GIS dataset from previous research (Pessel et al., 2001) on a sample square of about $100 \mathrm{~km}^{2}$ centered around a grain silo in Selommes (Beauce region, Loir-et-Cher). The Beauce region is famous for its cereals. This small region is almost exclusively devoted to farming; $75 \%$ of the land is occupied by agriculture and $80 \%$ of the farms are classified as producing 'cereals and protein oil crops', which is an exceptional proportion (44\% in the Loir-et-Cher region, $46 \%$ for the Centre region and 15\% for France as a whole). $63 \%$ of the arable land is planted with cereals and $13 \%$ with oilseed rape, the latter however by $67 \%$ of the farmers (Sausse, 2005). We start from a GIS shape file where the arable fields are represented as polygons (Figure 1). The sample square is less densely farmed (42\%) than the regional average (75\%). The modeled landscape counts 1,508 arable fields with an average field size of 2.8 ha and covering an area of 4,233 ha. This implies that the average field width is $168 \mathrm{~m}$ and the average distance between the fields amounts to $90 \mathrm{~m}$.

\section{$<$ INSERT Figure 1 HERE >}

Although our framework does not aim at representing any particular crop, we start from an indicative planting density of $13 \%$ similar to regional oilseed rape plantings (Sausse, 2005) and a GM adoption rate of 50\% to maximize the probability of a GM field being close to a non-GM field (Figure 1). We further vary these baseline assumptions by halving and increasing by half the adoption rate, i.e. to $25 \%$ and $75 \%$ respectively, and by halving and doubling the planting density, i.e. to $6 \%$ and $26 \%$ respectively. For each scenario, our CRP generates 10 iterations, yielding 50 independent random crop allocations. We furthermore assume that farmers plant the fields with pure seeds, i.e. free from GM contamination and comply with the set of alternative distance requirements in order to minimize crossfertilization. 


\section{Results}

Shadow factor estimates of individual GM fields are extremely variable and theoretically range from zero (when the field is not covered by any shadow) to infinity (when the field is entirely covered by a shadow). Therefore, we calculate the mean shadow factor at landscape level by dividing the total shadow area by the remaining GM area. Table 1 reports the mean shadow factors under a range of distance requirements and alternative planting scenarios. Mean shadow factors range from 0.00 to 0.34 , depending on distance requirements, planting densities and adoption rates. Under a planting density of $13 \%$ and an adoption rate of 50\%, mean shadow factors evolve from 0.01 to 0.14 if we progressively increase the distance requirement from $10 \mathrm{~m}$ to $100 \mathrm{~m}$. If we half the adoption rate (to $25 \%$ ), shadow factors increase twice as fast as the halo of the increased non-GM crop area casts a larger shadow on GM crop fields and further restricts the remaining GM area. This suggests that imposing wide distance requirements may substantially slow down early phases of GM crop adoption. If adoption levels increase by half (to 75\%), the non-GM area is halved and shadow factors increase half as fast due to the reduced shadow area and the fact that opportunity costs are amortized over a larger remaining GM area. A similar evolution of shadow factors is observed when halving the planting density (to 6\%), which spatially separates GM and nonGM fields from each other and reduces shadow areas in random crop allocation patterns. When doubling the planting density (to 26\%), the opposite occurs. The increased occurrence of spatial interactions dramatically increases the shadow area and reduces the remaining GM crop area, which more than doubles the shadow factors. In Figure 2, we visualize the nonlinear, convex evolution of mean shadow factors in function of distance requirements.

$<$ INSERT Table 1 AND Figure 2 HERE >

The low standard errors of the mean shadow factors at landscape level (ranging from 0.00 to 0.03 ) suggest that our constrained randomization procedure causes the Monte Carlo 
simulation to converge rapidly and to produce robust estimates after only 10 random draws. At field level, variability is much higher as mentioned before. Since shadow factors can be infinitely high, we do not report field level means nor standard errors, but instead report the descending cumulative densities of two shadow factor estimates (one third and one) on the shadow area. Remember that a shadow factor of one third implies that $25 \%$ of the GM field is covered by the shadow and a shadow factor of one implies that $50 \%$ of the GM field is covered by the shadow. We could alternatively interpret both area implications as if the GM rent on the field is eroded by respectively $25 \%$ or $50 \%$. At small distance requirements (10 $\mathrm{m}), 0-8 \%$ of the shadow area involves fields with a shadow factor greater than one and 14$29 \%$ with a shadow factor greater than one third. At high distance requirements (100 m), the densities evolve to respectively 52-65\% and 76-83\%. We visualize the evolution of both cumulative densities in Figure 3 and Figure 4. Compared to landscape level means (Figure 2), field level densities of shadow factors evolve in a more parallel way among the alternative planting scenarios. Moreover, the concave shape of the curves suggests that in the analyzed landscape, regardless of planting densities and adoption rates, distance requirements have the greatest effect in the interval from zero to about $50 \mathrm{~m}$, beyond which their marginal impact on densities seems to level off. At a distance requirement of $50 \mathrm{~m}$, about half (44-51\%) of the GM rents on the fields are at least halved (shadow factor greater than one). Finally, it is important to note that the densities only relate to the shadow area and that there is also a substantial share of the landscape which is not covered by shadow and, hence, not affected by SEACERs (featuring a shadow factor of zero). This explains the relatively modest mean shadow factors at landscape level, despite the important density of shadow area featuring high shadow factors (Table 1).

$<$ INSERT Figure 3 AND Figure 4 HERE > 


\section{Discussion}

\section{Opportunity costs}

The shadow factors reported in Table 1 are a measure for the opportunity costs borne by GM crop farmers per planted hectare of the GM crop as a result of complying with SEACERs. The magnitude of the opportunity costs is highly heterogeneous and depends on the GM rent and the rent obtained by planting the second-best alternative crop, which can be a non-GM variety of the same crop species or another crop. We assume that each random crop allocation is the result of heterogeneity in the landscape. The pattern of GM traits within the planting pattern of the crop is the result of farmers expecting that the utility of the GM rent will be higher than the utility of the rent of the non-GM crop. Similarly, the pattern of remaining non-GM crop plantings can be explained by farmers expecting that the non-GM crop will provide a higher utility than the GM crop. We could represent both utilities as two separate distributions, where the distribution of the paired differences would explain the adoption pattern in the landscape.

Some farmers will plant non-GM crops with the objective of supplying identity preserved (IP) crops in order to capture IP rents. IP rents stand for the total additional income generated by capturing price premiums for non-GM crops relative to GM crops. If there is a substantial demand for non-GM crops, this will be reflected by a market price premium for IP crops. However, if the content of GM material in non-GM crops exceeds the legal tolerance threshold of $0.9 \%$, they have to be labeled as 'containing GM material' and commercialized at the same price level as GM crops, without yielding any price premium (EC, 2003). Although IP price premiums are more or less homogenous among farmers as they are generated by the interaction of aggregate demand and supply on a differentiated market for GM and IP crops, IP rents are more heterogeneous as they depend, in addition, on heterogeneous yield levels. As identity preservation is costly, not all farmers planting non- 
GM crops will automatically supply IP crops, i.e. there exists a range of market equilibriums where a segment of farmers will supply non-IP non-GM crops (Lapan and Moschini, 2004).

Imposing SEACERs on GM farmers (following the newcomer principle) interferes with the GM crops' spatial utility distribution as it erodes GM rents by casting shadows on GM fields. However, SEACERs require shadows to be planted with other crops or non-GM crops of the same crop species and as shadows border the GM field and are entirely comprised within the distance requirement, it is reasonable to assume that they will be labeled as GM and commercialized at the same price level as GM crops. In other words, we assume that foregone GM rents on the shadow cannot be compensated through IP rents. For some GM farmers, the GM rents erode to the point that planting the second-best alternative becomes more attractive. As a result, these farmers will convert their entire field (total field conversion) to the second-best alternative instead of planting the shadow with non-GM crops and the remaining area with GM crops. But what is the second-best alternative in this case? The fact that these farmers intended to plant the GM crop on the field indicates that they expected to gain a positive GM rent, compared to planting the non-GM crop. Purely based on opportunity costs, we would argue that the GM rent would have to become zero (shadow factor of infinity) before these farmers become indifferent between planting GM crops and non-GM crops and that their second-best alternative would always be IP crops. However, the existence of operational, transaction and IP costs introduce inertia in the trade-off, such that an equilibrium may exist where these farmers will abandon GM crops, but not automatically switch to IP crops. 


\section{Domino-effect}

Regardless of the opportunity costs they generate, total field conversions substantially boost shadow areas and shadow factors in the landscape. However, the question is at which level of the shadow factor farmers start to generalize the shadow to their entire field. The question comes down to determining the critical shadow factor that triggers total field conversion. It is obvious that this critical level is heterogeneously distributed among fields in a landscape as it depends on the relative levels of stochastic GM, non-GM and IP rents. However, in order to gain insight on the maximal impact of total field conversion on shadow factors, we simulate a worst case scenario where we assume that the entire shadow area is subject to total field conversion. This scenario is not totally unrealistic; in reality it could occur if GM and IP rents (i) converge in the market (due to the competitive interaction between derived demand for GM seed and consumer demand for IP crops) and (ii) their utility distributions in the landscape are characterized by a strong positive covariance. Under these conditions, even small shadow factors induced by SEACERs may trigger large-scale total field conversions in a given landscape. We illustrate the worst-case scenario for a distance requirement of $50 \mathrm{~m}$, i.e. the isolation distance for maize proposed by France (Devos et al., 2008a).

In Table 2 we report the average shadow areas and shadow factors generated by imposing $50 \mathrm{~m}$ distance requirements on our random crop allocations under alternative planting scenarios in the extreme case of total field conversion. The 'Phase 1' rows report the initial shadow areas and shadow factors created by the SEACERs. However, if farmers convert their planting intentions on the shadow area from GM to non-GM, they may unleash a domino-effect (Demont et al., 2008b; Demont and Devos, 2008) in subsequent phases, i.e. an iterative spillover effect of farmers' planting intentions. In the absence of any regulation, GM and non-GM planting options would coexist in a population of farmers. Through compliance with SEACERs, some potential GM crop adopters have to convert their planting 
intentions. These new non-GM farmers might, in turn, restrict planting options and convert planting intentions of neighboring GM farmers (Phase 2). Subsequently, this might affect other GM farmers’ planting options and impinge on planting intentions, etc. (Phase 3-4), until all distance requirements between GM and non-GM fields are met at the landscape level. The 'Phase 2-4' rows in Table 2 report the cumulative impact of the domino-effect on the shadow area and the shadow factor. Depending on the scenario, the domino-effect expands the initial shadow area in Phase 1 with 2-41\% and reduces adoption with 9-33\% leaving clusters of GM crop planting intentions in the landscape. While the static relationship between the proportion of land available for GM crops and the distance requirement (e.g., in 'Phase 1' rows of Table 2) has been recognized in scholarly research on coexistence (Beckmann and Wesseler, 2007; Dolezel et al., 2005; Perry, 2002; Sanvido et al., 2008), the theoretical possibility of the domino-effect on adoption intentions has been largely ignored (Demont et al., 2008b; Demont and Devos, 2008).

\section{$<$ TABLE 2 ABOUT HERE >}

In the baseline scenario, the initial shadow factor amounts to 0.42 and increases to 0.50 as a result of the domino-effect on the shadow area $(+16 \%)$ and the subsequent area restriction for GM crops (-33\%). Halving the adoption rate more than doubles the initial shadow factor to 1.08 , as the shadow area is amortized over half of the baseline GM area, which is further restricted by the domino-effect $(-52 \%)$. However, due to the lower density of GM fields in the landscape, the domino-effect has a modest impact on the shadow area (+9\%) and on the shadow factor, which increases to 1.20. Increasing the adoption rate by half generates a lower initial shadow factor of 0.25 , as the shadow area is amortized over a larger GM area, but the high GM field density entails the most prominent domino-effect on the shadow area $(+41 \%)$ among all scenarios, increasing the shadow factor to 0.39 . Halving the planting density yields the lowest shadow factor $(0.23-0.24)$ among all scenarios, which is 
hardly affected by any domino-effect (+3\%). Doubling the planting density yields the highest initial shadow factor (1.37), but also generates a substantial domino-effect on the shadow area $(+18 \%)$ and dramatically restricts the GM area $(-66 \%)$, which raises the shadow factor to 2.05 .

When we compare Table 1 with Table 2, we observe that total field conversion at its maximum extent, combined with a domino-effect has the potential to dramatically boost the shadow factors, i.e. by one order of magnitude. However, in reality the growth of the shadow factor may be mitigated by partial field conversion decisions during each phase of the domino-effect. Hence, at the market equilibrium, the mean shadow factor may reach a value somewhere between the lower estimates in Table 1 and the upper estimates in Table 2.

\section{Regulatory rigidity versus regulatory flexibility}

In ex post liability schemes, the newcomer principle enforces GM crop adopters to redress incurred economic harm once the content of GM material in a non-GM crop product exceeds the legal tolerance threshold of $0.9 \%$ (EC, 2003). In ex ante coexistence regulations, the newcomer principle could however be applied on two alternative areas of responsibility. Applying it on the civilian responsibility obliges GM crop farmers to undertake the coexistence measures, whereas applying it on the financial responsibility enforces them only to bear the financial burden of these measures, regardless of who is implementing them. Applying the newcomer principle on both the civilian and the financial responsibility introduces regulatory rigidity in SEACERs, whilst applying it on the financial responsibility only entails regulatory flexibility: it allows farmers that adopt GM crops to contract out the implementation of coexistence measures to their neighbors with non-GM crop planting intentions in return for a compensatory payment in case the latter option is cheaper. 
Proposition 1: The larger the distance requirement the higher the probability that a GM crop field predominantly or entirely overlaps with the shadow of a non-GM crop (Table 1), the more farmers will tend to apply total field conversion in response to SEACERs and the more the shadow factor will evolve towards the upper estimates (Table 2). The smaller the distance requirement and the more flexible the SEACERs, the higher the occurrence of partial field conversions as farmers will be more inclined to search for a border solution in coordination with their neighbors and the more the shadow factor will evolve towards the lower estimates (Table 1).

\section{Isolation distances versus pollen barriers}

Most EU member states' SEACERs include (i) minimal isolation distance requirements, implemented by 10 member states, in combination with or as an alternative to (ii) pollen barriers planted with non-GM crops of the same species between GM and non-GM fields, implemented by six member states (EC, 2006). Isolation distances are rules governing the minimum distance between GM and non-GM crop fields of the same species. Pollen barriers, on the other hand, are coexistence measures that rely on field margins that are planted with non-GM crops of the same species and of which the harvest will need to be labeled as 'GM'. They serve as cross-fertilization zones between GM and non-GM varieties of the same crop and can be planted on donor or recipient fields (Demont and Devos, 2008). As pollen barriers are planted with non-GM varieties of the same crop, they are more interchangeable among neighboring farmers that grow the same crop and, therefore, bettersuited to build in flexibility into coexistence measures than isolation distances. Furthermore, proposed pollen barriers are typically one order of magnitude smaller $(10-20 \mathrm{~m})$ than proposed isolation distances (100-200 m) and therefore encourage voluntary coordination among neighboring farmers (Devos et al., 2008a). 
Scientific evidence suggests that the extent of cross-fertilization in maize is reduced much more effectively by a pollen barrier than an isolation perimeter of bare ground of the same width (Della Porta et al., 2008). The effectiveness of 10-20 m pollen barriers, ideally planted around the recipient field (Ceddia et al., 2009; Gustafson et al., 2006; Messeguer et al., 2006; Pla et al., 2006; Weber et al., 2007; Weekes et al., 2007), is shown to be comparable to $50 \mathrm{~m}$ isolation distances of bare ground (Devos et al., 2005; Hüsken et al., 2007; Messéan et al., 2006; Messeguer et al., 2006; Sanvido et al., 2008; Van De Wiel and Lotz, 2006). Sanvido et al.'s (2008) recent meta-analysis of 13 studies concluded that an isolation perimeter of $50 \mathrm{~m}$ would be sufficient to keep cross-fertilization levels below the $0.5 \%$ at the border of the recipient maize field.

In the case of flexible pollen barriers, we consider four practical solutions, depending on whether the pollen barrier is cultivated on the GM field (System 1) or on the non-GM field (System 2) and whether it is planted, cultivated and/or harvested by the owner (System a) or the neighbor (System b) of the field. While the placement of the pollen barrier (System 1 versus System 2) determines the magnitude of the opportunity costs, the transaction and operational costs may vary among the four systems and also among regions, farmers and fields. In System 1a, the GM farmer plants and cultivates a pollen barrier with non-GM crops on his GM field next to his neighbor's non-GM field. However, in the context of herbicide tolerant (HT) crops, maintaining two different weed control systems on a single field may not be practical for organizational reasons. Therefore, in System 1b it is the non-GM farmer who plants and cultivates a pollen barrier on the GM farmer's field. The latter reimburses part of the former's cultivation costs (sowing and herbicide treatments), harvests his entire field, including the pollen barrier, and sells his crops as GM. ${ }^{2}$ In either version of System 1, the GM farmer foregoes the GM rent on his pollen barrier. In System 2a, the non-GM farmer separately harvests his adjacent margins, which serve as pollen barriers, next to the 
neighboring farmer's GM fields, and delivers them to the collector as 'GM'. However, he foregoes any scale economies of harvesting and selling his full non-GM crop production in a single lot, such as in System 1b. Therefore, a variant which takes advantage of scale economies is System 2b: the GM farmer first harvests the field margin on the non-GM farmer's field (with a clean harvester to avoid contamination of subsequent crop rotations) and sells the harvested crops in a single lot with the rest of his GM crops. In either version of System 2, the GM farmer has to compensate the neighboring non-GM farmer for the IP rent foregone. In System b, there is a market price risk which can be borne by either the GM or the non-GM farmer, depending on the contract between both parties. Moreover, the system introduces transaction costs due to moral hazard (e.g., see Allen and Lueck, 1998). In System 2b, the GM farmer has incentives for underreporting yields of non-GM crops on his neighbor's field. In System 1b, the GM farmer pays the non-GM farmer for his cultivation services, but since the latter is not the residual claimant of the barrier crops, he has incentives to lower the quality of his services. System a avoids these transaction costs, but introduces loss of scale economies. In System 1a, for example, the GM farmer has to manage two different weed management systems on his field and in System 2a, the non-GM farmer has to separately sell limited quantities of potentially contaminated non-GM crops to GM-labeled outlets. ${ }^{3}$ Finally, additional transaction costs may arise in collecting information, planning and negotiating coexistence measures among farmers.

We can reasonably assume that farmers will choose the system that minimizes total (opportunity, transaction and operational) costs in the long run. If, for example, System 1a turns out to be the most widely applied system despite GM rents superior to IP rents, this would suggest that transaction and operational costs are minimized under this system, i.e. the additional management costs owing to scale inefficiency are inferior to the transaction costs from farmer coordination. 
Proposition 2: Pollen barriers induce lower shadow factors than isolation distances as they need not to be as large to achieve a similar rate of cross-fertilization and they are more compatible with regulatory flexibility than isolation distances (Proposition 1).

\section{Proportionality condition}

In European law, the principle of proportionality has been borrowed from German and French law, and means striking a balance between the advantages a regulation provides and the constraints that it imposes (Emiliou, 1996). Remember that according to the EC (2003), coexistence regulations focus in the first place on farmers. They aim at preserving farmers' production options among a set of alternative systems, yet without going beyond what is necessary in order to ensure that adventitious traces of GMOs stay below the labeling threshold in order to avoid any unnecessary burden for the farmers concerned. In the case of maize, for instance, isolation distances proposed by EU member states range from $15 \mathrm{~m}$ to $800 \mathrm{~m}$ (Devos et al., 2008a), while scientific evidence suggests that $50 \mathrm{~m}$ is sufficient to achieve the required threshold.

The benefits of the regulations are that they protect the segment of IP crop farmers against foregone IP crop production options (loss of option value) and foregone IP rents, at the cost of constraining the segment of GM farmers' planting options (loss of option value and GM rents). Consequently, the benefits are a function of the IP rents, while the costs are a function of the GM rents. The more IP rents stochastically converge to GM rents, the more GM farmers will be able to reduce opportunity costs by compensating their GM rents foregone through IP rents. The shadow factors may increase due to a higher occurrence of total field conversions, but at the same time the opportunity costs per unit of shadow area decline. Under costless IP and costless operations and transactions involved in planting both GM and non-GM crops on the same field through partial field conversion, whether both 
effects cancel each other out is ambiguous. However, the higher the costs of IP and the operational and transaction costs involved in planting both GM and non-GM crops on the field, the more inertia are created and the larger the segment of non-GM non-IP crop farmers becomes. The latter farmer segment foregoes both the GM and the IP rent and the larger this segment the more disproportional the regulations become. Declining IP rents will have a similar effect on this farmer segment and on the proportionality of the regulations.

Flexible regulations based on pollen barriers encourage cost-minimizing behavior of farmers. If IP rents are negligible compared to GM rents, GM farmers will have incentives to propose System 2 to their neighboring farmers. They might even persuade the latter to convert their fields to GM. If IP rents rise, coexistence costs will rise proportionally until farmers switch to System 1 as System 2 becomes more expensive. Further rising IP rents will not affect coexistence costs under System 1. Hence, regulatory flexibility implies that the costs of SEACERs become a function of both the GM rents (System 1) and the IP rents (System 2) as farmers will tend to choose the system that induces the lowest costs.

Proposition 3: Flexible regulations based on pollen barriers are more likely to respect the proportionality condition because they induce both smaller shadow factors (Proposition 2) and smaller opportunity costs, as they encourage cost-minimizing behavior of farmers to a higher extent than rigid regulations based on isolation distances.

Strengths and limitations of the framework

Our framework is built on three basic assumptions: (i) compliance, i.e. farmers comply with the proposed SEACERs, (ii) effectiveness, i.e. the proposed SEACERs are effective in minimizing cross-fertilization and keeping the GM content of non-GM crops below the EU threshold of 0.9\%, and (iii) the newcomer principle (EC, 2003) holds, i.e. GM farmers will 
bear the costs of coexistence measures and compensate non-GM farmers for incurred losses of crop purity. Its major strength is probably its simplicity; its major limitation is related to data requirements.

Compared to Demont et al. (2008b), our framework presents four improvements. First, it more explicitly demonstrates the value of the shadow factor in analyzing the spatial impact of SEACERs. Secondly, while the results of Demont et al. (2008b) are implicitly based on the concept of the shadow factor, the nominator of the latter is based on the newly created shadow area in each phase, while the denominator is calculated as the total area intended to be planted with GM crops. In this paper, in contrast, we propose the cumulative shadow area as the correct nominator and the remaining GM area as the correct denominator, which more correctly represents the growth of shadow factors as a result of the domino-effect (Table 2). Thirdly, it captures better the variability of estimates by incorporating a wider range of scenarios by varying planting densities, adoption rates and distance requirements. Finally, we provide additional insights by reporting cumulative density properties of shadow factors under increasing distance requirements (Table 1, Figure 3 and Figure 4).

GIS datasets are difficult to obtain due to their proprietary nature and rarely contain a complete set of spatially linked information on land tenure, farmer practices, intentions and strategies of coordination, production costs, etc. The absence of land tenure records in the GIS database of our sample area forced us to treat all fields as independent. Randomly assigning GM and non-GM crop fields among these fields, subject to a set of planting constraints, also generates on-farm inter-field coexistence situations, which are generally not classified under coexistence (Stein and Rodríguez-Cerezo, 2007). Therefore, our assumption of independent fields probably biases shadow areas and factors upwards. Secondly, if GM content of IP crops is measured at the harvest or silo level instead of the field level, farmers may dilute the GM content of their non-GM crops on-farm without the need of SEACERs, 
i.e. by mixing the harvests of their contaminated and uncontaminated fields (Ceddia et al., 2007; Ceddia et al., 2009). Thirdly, despite the fact that land tenure is relatively scattered in the analysed region (Sausse, 2005), we expect that minimization of coexistence costs will drive clustering of farms in the medium and long-run (Beckmann and Wesseler, 2007; Furtan et al., 2007). As a result, our overestimation originates both from the independence assumption and from the constrained randomization procedure. Therefore, our shadow factor estimates have to be interpreted as upper values of the expected medium and long-run values.

A further limitation of our proposed framework is the fact that our shadow factors are based on a single landscape. In order to relax this limitation and widen somewhat the range of landscape configurations captured by our framework, we varied planting densities from 6\%, i.e. comparable to oilseed rape planting in the Fife region of Scotland (Copeland and Kasamba, 2007), to its fourfold of $26 \%$, i.e. consistent with a four-year cropping cycle. However, this variation still failed to capture alternative degrees of land fragmentation as planting density does not affect the average field size in our sample. Therefore, research efforts need to be done in order to reproduce our spatial methodology for different landscape configurations. Another solution could be to summarize landscape configuration in a single measure such as the concept of the land fragmentation index. In the literature, different indices of land fragmentation have been proposed, e.g. based on the number and size of plots, between-plot distances, and combining size and shape (Gonzalez et al., 2004). Future research could provide a useful and innovative contribution by mathematically deriving our shadow factor as a function of an index of land fragmentation. This will enable efficiently reproducing our framework for a variety of European landscapes and will provide valuable information for policy makers on the compared spatial impact of alternative SEACERs.

An additional issue which is not captured in our framework is irreversibility, a weakness which our framework shares with most of the literature reviewed in our 
introduction. The issue of irreversibility has been widely applied on regulatory approval and adoption of GM crops (Demont et al., 2004; Demont et al., 2005; Hennessy and Moschini, 2006; Scatasta et al., 2006; Weaver and Wesseler, 2004; Wesseler et al., 2007), but less frequently on the regulation of coexistence (Beckmann et al., 2006), unless implicitly through the analyzed time dimension (Belcher et al., 2005; Colbach et al., 2009). By analyzing a single season, our framework implicitly relies on the compliance and effectiveness assumptions, which suppose that the modeled SEACERs are sufficient for maintaining seed purity and limiting the development of volunteers over time. In the case of oilseed rape, this is a strong assumption which implicitly ignores additional costs due to management complications over time. Messéan et al. (2007) observed that over time the rate of GM seeds admixture in the harvest largely exceeded the European threshold in a third of the cases and conclude that "Unless appropriate management and agronomical guidelines to manage volunteers are implemented, it will indeed be hazardous for a farmer to go back to a conventional non-GM farming system, even 5 years after the last transgenic OSR harvest” (p. 121). Moreover, oilseed rape has a number of cross-compatible wild and weedy relatives which increases the possibilities for the establishment of a feral population of the crop. In contrast, maize has no cross-compatible wild/weedy relatives in the European Union (Eastham and Sweet, 2002), whilst wheat has some potential partners (Loureiro et al., 2006). Hence, while our framework focused only on the spatial dimension, future research on coexistence will need to assess the impact of alternative SEACERs in the temporal dimension. It may well be that for some crops inclusion of time will argue for more conservative SEACERs.

Another data constraint is related to the ex ante nature of the coexistence question in Europe, which inspired us to split the problem into two parts and focus on the spatial component, while exogeneizing the market component. As long as the EU has limited 
experience with a differentiated market of GM and IP crops, policy makers can use the concept of the shadow factor as a proxy variable for opportunity costs. SEACERs can be designed based on a meta-analysis of distance requirements from cross-fertilization studies. Once policy makers have established a set of shadow factors for a variety of landscapes, they can easily compare the regional impact of alternative SEACERs through a single measure. GM rents, although heterogeneous, have been more or less established after a decade of global GM crop adoption (Demont et al., 2007). The literature reports GM rent estimates for maize ranging from €23/ha in Hungary and €31/ha in the Czech Republic (Demont et al., 2008a) to €47/ha in Spain (Demont and Tollens, 2004) and €70/ha in France (ORAMA, 2007), while estimates for oilseed rape range from $€ 29 /$ ha in Hungary to $€ 55-56 /$ ha in the Czech Republic and France (Demont et al., 2008a; Demont et al., 2008b). Future IP rents, on the other hand, are still uncertain in the EU, owing to limited experience with large-scale diffusion of GM crops. However, they can be approximated through analogy in comparable import markets (e.g., soybeans in the EU), or not approximated at all and replaced by breakeven values (e.g., equal to GM rents), as illustrated by Demont et al. (2008b). Break-even assumptions are widely used strategies in ex ante impact assessment for assuming away and avoiding imposing strong prior assumptions on unknown or highly uncertain parameters (Demont et al., 2004) or for sharpening a model's prediction on potential quantitative results (Moschini et al., 2005). To date, price differentials for GM-free crops have been weak in international agricultural markets (Falck-Zepeda, 2006; Foster and French, 2007). This does not imply that, under weak market signals for IP crops, the entire European landscape will be planted with GM crops and crowd out IP crop production. Experience has shown that GM crop adoption is usually incomplete. ${ }^{4}$

Finally, the latter leads us to a limitation of our three basic assumptions (compliance, effectiveness, and the newcomer principle), which excludes the possibility of consumers with 
strong preferences for IP crops being prevented from having access to IP crops as a result of cross-fertilization due to under-regulation of coexistence. ${ }^{5}$ Indeed, in this paper we argue that flexible SEACERs are preferable to rigid SEACERs, assuming that they are both complied with and effective. Hence, if proposed distance requirements were to be insufficient, coexistence would be under-regulated and this would engender important welfare losses for consumers of IP crops. However, over-regulation could entail similar welfare losses. From Table 2 we would tend to conclude that rigid SEACERs protect and favor IP crop farmers and consumers and harm GM crop farmers. However, if consumer preferences for IP crops are not competitive to farmer preferences for GM crops, i.e. if they generate smaller IP incentives than GM incentives for farmers, an inverse domino-effect could occur triggered by GM farmers who try to convince their non-GM neighbors to revisit their planting decisions. It is possible that both types of domino-effect will coexist and complement regional specialization in the European landscape. It is important to note that the guidelines of the EC define coexistence only in terms of farmers, but future research efforts are needed to analyze coexistence from the perspective of the consumer as well.

\section{Conclusions}

In its struggle to implement coherent coexistence regulations on GM and non-GM crops in all member states, the EU has clearly emphasized that any approach needs to be proportionate to the aim of achieving coexistence. We developed a spatial framework for analyzing the proportionality of alternative spatial ex ante coexistence regulations (SEACERs) based on a geographic model of a real landscape in Central France. We introduced the novel concept of shadow factor as a measure for farmers' opportunity costs of complying with SEACERs in a given landscape. Our empirical findings led us to advance the proposition that flexible regulations based on pollen barriers are more likely to respect the proportionality condition 
than rigid regulations based on isolation distances. Particularly in early adoption stages, imposing wide and rigid SEACERs may substantially slow down GM crop adoption. This is consistent with the survey of Skevas et al. (2009), who reported that 44\% of the surveyed GM and non-GM maize producers in Portugal stated difficulties in applying the SEACERs. The authors concluded that, among other factors, the rigidity of SEACERs seems to hamper GM maize adoption in Portugal and in its current form reduces rather than supports coexistence. However, in the case of moderate SEACERs imposed on large farms in the Brandenburg region in Germany, SEACERs seem to impose a smaller burden on early GM maize adopters (Consmüller et al., 2009).

Our findings argue for incorporating a certain degree of flexibility into SEACERs by advising pollen barrier agreements between farmers rather than imposing rigid isolation distances on GM farmers. The empirical questions of proportionality and flexibility have been largely ignored in the literature on coexistence and provide timely information for EU policy makers. Authorities may be reluctant to adopt flexible ex ante regulations, but in the absence of clear market signals for IP crops, regulatory rigidity should be shifted from ex ante to ex post to avoid jeopardizing the economic incentives for coexistence in EU agriculture (Demont and Devos, 2008). Germany for example - perhaps inspired by their advisory speed limits in traffic law - is currently planning to introduce flexibility into its coexistence regulations, an issue which is highly debated among politicians and interest groups (Crowley, 2008). German traffic law also shifts regulatory rigidity from ex ante to ex post. In case of a road accident, the driver can be held ex post liable for negligence if he did not comply with the ex ante speed limit during the accident (Müller, 2007). The same model could be applied in coexistence regulations; if any incident of GM contamination occurs and affects the welfare of farmers and consumers, GM farmers are held ex post liable for 
negligence and have to pay ex post tort liability costs if they did not comply with the ex ante coexistence regulations (Beckmann et al., 2006).

Finally, coexistence of agricultural production systems is a complex research subject and our proposed framework is just a small building stone in an emerging field of policy economics of coexistence. Further research is needed to forecast the market response to the introduction of GM crops in Europe and to link our framework to a generalized index of land fragmentation. However, the major weakness of the framework remains due to the ex ante nature of the coexistence problem in Europe and therefore, we hope that it may inspire other researchers to go further and obtain the relevant data to analyze the problem in its entirety. 


\section{References}

Alexander, C., Fernandez-Cornejo, J., Goodhue, R.E., 2002. Determinants of GMO use: A survey of Iowa corn-soybean farmers' acreage allocation. In: Santaniello, V., Evenson, R.E., Zilberman, D. (eds.), Market Development for Genetically Modified Foods. CAB International, Wallingford, pp. 127-139.

Allen, D.W., Lueck, D., 1998. The nature of the farm. Journal of Law and Economics 41(2), 343-386.

Beckmann, V., Soregaroli, C., Wesseler, J., 2006. Coexistence rules and regulations in the European Union. American Journal of Agricultural Economics 88(5), 1193-1199.

Beckmann, V., Wesseler, J., 2007. Spatial dimension of externalities and the Coase theorem: Implications for co-existence of transgenic crops. In: Heijman, W. (ed.), Regional Externalities. Springer, Berlin Heidelberg New York, pp. 223-242.

Belcher, K., Nolan, J., Phillips, P.W.B., 2005. Genetically modified crops and agricultural landscapes: Spatial patterns of contamination. Ecological Economics 53, 387-401.

Breustedt, G., Muller-Scheessel, J., Latacz-Lohmann, U., 2008. Forecasting the adoption of GM oilseed rape: Evidence from a discrete choice experiment in Germany. Journal of Agricultural Economics 59(2), 237-256.

Ceddia, M.G., Bartlett, M., Perrings, C., 2007. Landscape gene flow, coexistence and threshold effect: The case of genetically modified herbicide tolerant oilseed rape (Brassica napus). Ecological Modelling 205(1-2), 169-180.

Ceddia, M.G., Bartlett, M., Perrings, C., 2009. Quantifying the effect of buffer zones, crop areas and spatial aggregation on the externalities of genetically modified crops at landscape level. Agriculture, Ecosystems and Environment 129(1-3), 65-72. 
Colbach, N., Monod, H., Lavigne, C., 2009. A simulation study of the medium-term effects of field patterns on cross-pollination rates in oilseed rape (Brassica napus L.). Ecological Modelling 220(5), 662-672.

Consmüller, N., Beckmann, V., Schleyer, C., The role of coordination and cooperation in early adoption of GM crops: The case of Bt maize in Brandenburg, Germany. AgBioForum (in press).

Copeland, J.E., Kasamba, E., 2007. Economics of coexistence measures of GM and conventional crops: Oilseed rape in Fife (Scotland). In: Stein, A.J., Rodríguez-Cerezo, E. (eds.), Third International Conference on Coexistence Between Genetically Modified (GM) and Non-GM Based Agricultural Supply Chains, Seville (Spain), 2021 November 2007: Book of Abstracts. Office for Official Publications of the European Communities, Luxembourg, pp. 149-152.

Crowley, L., Germany enables easier GM cultivation, http://www.foodnavigator.com/news/ ng.asp?n=82867-monsanto-germany-gm-crops, 29-1-2008.

Damgaard, C., Kjellsson, G., 2005. Gene flow of oilseed rape (Brassica napus) according to isolation distance and buffer zone. Agriculture, Ecosystems and Environment 108, 291-301.

Della Porta, G., Ederle, D., Bucchini, L., Prandi, M., Verderio, A., Pozzi, C., 2008. Maize pollen mediated gene flow in the Po valley (Italy): Source-recipient distance and effect of flowering time. European Journal of Agronomy 28, 255-265.

Demont, M., Cerovska, M., Daems, W., Dillen, K., Fogarasi, J., Mathijs, E., Muška, F., Soukup, J., Tollens, E., 2008a. Ex ante impact assessment under imperfect information: Biotechnology in New Member States of the EU. Journal of Agricultural Economics 59(3), 463-486. 
Demont, M., Daems, W., Dillen, K., Mathijs, E., Sausse, C., Tollens, E., 2008b. Regulating coexistence in Europe: Beware of the domino-effect! Ecological Economics 64(4), 683-689.

Demont, M., Devos, Y., 2008. Regulating coexistence of GM and non-GM crops without jeopardizing economic incentives. Trends in Biotechnology 26(7), 353-358.

Demont, M., Dillen, K., Mathijs, E., Tollens, E., 2007. GM crops in Europe: How much value and for whom? EuroChoices 6(3), 46-53.

Demont, M., Tollens, E., 2004. First impact of biotechnology in the EU: Bt maize adoption in Spain. Annals of Applied Biology 145(2), 197-207.

Demont, M., Wesseler, J., Tollens, E., 2004. Biodiversity versus transgenic sugar beet: The one Euro question. European Review of Agricultural Economics 31(1), 1-18.

Demont, M., Wesseler, J., Tollens, E., 2005. Irreversible costs and benefits of transgenic crops: What are they? In: Wesseler, J. (ed.), Environmental Costs and Benefits of Transgenic Crops. Springer, Dordrecht, NL, pp. 113-122.

Devos, Y., Demont, M., Sanvido, O., 2008a. Coexistence in the EU - return of the moratorium on GM crops? Nature Biotechnology 26(11), 1223-1225.

Devos, Y., Reheul, D., De Schrijver, A., 2005. The co-existence between transgenic and nontransgenic maize in the European Union: A focus on pollen flow and crossfertilization. Environmental Biosafety Research 4(2), 71-87.

Devos, Y., Reheul, D., De Schrijver, A., Cors, F., Moens, W., 2004. Management of herbicide-tolerant oilseed rape in Europe: A case study on minimizing vertical gene flow. Environmental Biosafety Research 3(3), 135-148.

Devos, Y., Reheul, D., Thas, O., De Clercq, E., Cougnon, M., Cordemand, K., 2007. Implementing isolation perimeters around genetically modified maize fields. Agronomy for Sustainable Development 27, 155-165. 
Devos, Y., Thas, O., Cougnon, M., De Clercq, E., Cordemans, K., Reheul, D., 2008b. Feasibility of isolation perimeters for genetically modified maize on an intra-regional scale in Flanders. Agronomy for Sustainable Development 28.

Dillen, K., Demont, M., Tollens, E., 2008. Modelling heterogeneity to estimate the ex ante value of biotechnology innovations. In: Proceedings from the $12^{\text {th }}$ EAAE (European Association of Agricultural Economists) Congress, Ghent, 26-29 August 2008.

Dolezel, M., Pascher, K., Grabherr, G., 2005. Regionality as a key parameter for co-existence of genetically modified maize with conventional and organic maize. In: Messéan, A. (ed.), Proceedings of the $2^{\text {nd }}$ International Conference on Co-Existence Between GM and Non-GM Based Agricultural Supply Chains. Agropolis Productions, Montpellier, pp. 203-206.

Eastham, K., Sweet, J., 2002. Genetically Modified Organisms (GMOs): The Significance of Gene Flow Through Pollen Transfer, European Environment Agency, Copenhagen, Denmark, Environmental Issue Report nº 28.

EC, 2003. Commission Recommendation of 23 July 2003 on guidelines for the development of national strategies and best practices to ensure the coexistence of genetically modified crops with conventional and organic farming. Official Journal of the European Communities L189, 36-47.

EC, 9-3-2006. Report on the Implementation of National Measures on the Coexistence of Genetically Modified Crops With Conventional and Organic Farming, Commission of the European Communities, Brussels, Communication from the Commission to the Council and the European Parliament nº 104.

Emiliou, N., 1996. Principle of Proportionality In European Law: A Comparative Study. Kluwer Law International, London. 
Falck-Zepeda, J.B., 2006. Coexistence, genetically modified biotechnologies and biosafety: Implications for developing countries. American Journal of Agricultural Economics 88(5), 1200-1208.

Feder, G., Just, R.E., Zilberman, D., 1985. Adoption of agricultural innovations in developing countries: A survey. Economic Development and Cultural Change 33(2), 255-298.

Foster, M., French, S., 2007. Market Acceptance of GM Canola, Australian Bureau of Agricultural and Resource Economics, Canberra, ABARE Research Report nº 07.5.

Furtan, W.H., Guzel, A., Weseen, A.S., 2007. Landscape clubs: Co-existence of genetically modified and organic crops. Canadian Journal of Agricultural Economics 55(2), 185195.

Gómez-Barbero, M., Berbel, J., Rodríguez-Cerezo, E., 2008. Bt corn in Spain - the performance of the EU's first GM crop. Nature Biotechnology 26, 384-386.

Gonzalez, X.P., Alvarez, C.J., Crecente, R., 2004. Evaluation of land distributions with joint regard to plot size and shape. Agricultural Systems 82(1), 31-43.

Gustafson, D.I., Brants, I.O., Horak, M.J., Remund, K.M., Rosenbaum, E.W., Soteres, J.K., 2006. Empirical modeling of genetically modified maize grain production practices to achieve European Union labeling thresholds. Crop Science 46, 2133-2140.

He, H., Dezonia, B., Mladenoff, D., 2000. An aggregation index (AI) to quantify spatial patterns of landscapes. Landscape Ecology 15(7), 591-601.

Hennessy, D.A., Moschini, G., 2006. Regulatory actions under adjustment costs and the resolution of scientific uncertainty. American Journal of Agricultural Economics 88(2), 308-323.

Hoyle, M., Cresswell, J.E., 2007. The effect of wind direction on cross-polination in windpollinated GM crops. Ecological Applications 17(4), 1234-1243. 
Hüsken, A., Ammann, K., Messeguer, J., Papa, R., Robson, P., Schiemann, J., Squire, G., Stamp, P., Sweet, J., Wilhelm, R., 2007. A major European synthesis of data on pollen and seed mediated gene flow in maize in the SIGMEA project. In: Stein, A.J., Rodríguez-Cerezo, E. (eds.), Third International Conference on Coexistence Between Genetically Modified (GM) and Non-GM Based Agricultural Supply Chains, Seville (Spain), 20-21 November 2007: Book of Abstracts. Office for Official Publications of the European Communities, Luxembourg, pp. 53-56.

Hüsken, A., Dietz-Pfeilstetter, A., 2007. Pollen-mediated intraspecific gene flow from herbicide resistant oilseed rape (Brassica napus L.). Transgenic Research 16, 557569.

Lapan, H.E., Moschini, G., 2000. Incomplete adoption of a superior innovation. Economica 67, 525-542.

Lapan, H.E., Moschini, G., 2004. Innovation and trade with endogenous market failure: The case of genetically modified products. American Journal of Agricultural Economics 86(3), 634-648.

Loureiro, I., Escorial, M.C., García-Baudín, J.M., Chueca, M.C., 2006. Evidence of natural hybridization between Aegilops geniculata and wheat under field conditions in Central Spain. Environmental Biosafety Research 5, 105-109.

Marra, M.C., Piggott, N.E., 2006. The value of non-pecuniary characteristics of crop biotechnologies: A new look at the evidence. In: Just, R.E., Alston, J.M., Zilberman, D. (eds.), Regulating Agricultural Biotechnology: Economics and Policy. Springer, New York, pp. 145-177.

Messéan, A., Angevin, F., Gómez-Barbero, M., Menrad, K., Rodríguez-Cerezo, E., 2006. New Case Studies on the Coexistence of GM and Non-GM Crops in European 
Agriculture, European Communities, Luxembourg, Technical Report nº EUR 22102 EN.

Messéan, A., Sausse, C., Gasquez, J., Darmency, H., 2007. Occurrence of genetically modified oilseed rape seeds in the harvest of subsequent conventional oilseed rape over time. European Journal of Agronomy 27, 115-122.

Messeguer, J., Peñas, G., Ballester, J., Bas, M., Serra, J., Salvia, J., Palaudelmàs, M., Melé, E., 2006. Pollen-mediated gene flow in maize in real situations of coexistence. Plant Biotechnology Journal 4, 633-645.

Moschini, G., Bulut, H., Cembalo, L., 2005. On the segregation of genetically modified, conventional, and organic products in European agriculture: A multi-market equilibrium analysis. Journal of Agricultural Economics 56(3), 347-372.

Müller, D., 2007. Geschwindigkeit als Unfallursache. Zeitschrift für die Praxis des Verkehrsjuristen 1, 1-6.

Munro, A., 2008. The spatial impact of genetically modified crops. Ecological Economics 67(4), 658-666.

Oehmke, J.F., Wolf, C.A., 2004. Why is Monsanto leaving money on the table? Monopoly pricing and technology valuation distributions with heterogeneous adopters. Journal of Agricultural and Applied Economics 36(3), 705-718.

ORAMA, GM maize in the field: Conclusive results, http:/www.agpm.com/en/iso_album/ technical_results_btmaize_2006.pdf, 2007.

Perry, J.N., 2002. Sensitive dependencies and separation distances for genetically modified herbicide-tolerant crops. Proceedings of the Royal Society of London. Series B: Biological Sciences 269, 1173-1176. 
Pessel, F.D., Lecomte, J., Emeriau, V., Krouti, M., Messéan, A., Gouyon, P.H., 2001. Persistence of oilseed rape (Brassica napus L.) outside of cultivated fields. Theoretical and Applied Genetics 102(6-7), 841-846.

Pla, M., La Paz, J.-L., Peñas, G., García, N., Palaudelmàs, M., Esteve, T., Messeguer, J., Melé, E., 2006. Assessment of real-time PCR based methods for quantification of pollen-mediated gene flow from GM to conventional maize in a field study. Transgenic Research 15, 219-228.

Sanvido, O., Widmer, F., Winzeler, M., Streit, B., Szerencsits, E., Bigler, F., 2008. Definition and feasibility of isolation distances for transgenic maize cultivation. Transgenic Research 17(3), 317-335.

Sausse, C., 2005. Case Study Beauce/Rapeseed, SIGMEA Project, Grignon, SIGMEA Deliverables Workpackage 7.1.

Scatasta, S., Wesseler, J., Demont, M., 2006. Irreversibility, uncertainty, and the adoption of transgenic crops: Experiences from applications to HT sugar beets, HT corn and Bt corn. In: Just, R.E., Alston, J.M., Zilberman, D. (eds.), Regulating Agricultural Biotechnology: Economics and Policy. Springer, New York, pp. 327-352.

Skevas, T., Wesseler, J., Fevereiro, P., Coping with ex-ante regulations for planting Bt maizeThe Portuguese experience. AgBioForum (in press).

Stein, A.J., Rodríguez-Cerezo, E., 2007. Third International Conference on Coexistence Between Genetically Modified (GM) and Non-GM Based Agricultural Supply Chains, Seville (Spain), 20-21 November 2007: Book of Abstracts. Office for Official Publications of the European Communities, Luxembourg.

Sunding, D.L., Zilberman, D., 2001. The agricultural innovation process: Research and technology adoption in a changing agricultural sector. In: Gardner, B.L., Rausser, 
G.C. (eds.), Handbook of Agricultural Economics, Volume 1. Elsevier, Amsterdam, pp. 207-261.

Van De Wiel, C.C.M., Lotz, L.A.P., 2006. Outcrossing and coexistence of genetically modified with (genetically) unmodified crops: A case study of the situation in the Netherlands. NJAS Wageningen Journal of Life Sciences 54(1), 17-35.

Weaver, R.D., 2004. R\&D incentives for GM seeds: restricted monopoly, non-market effects, and regulation. In: Evenson, R.E., Santaniello, V. (eds.), The Regulation of Agricultural Biotechnology. CAB International, Wallingford, UK, pp. 143-151.

Weaver, R.D., Wesseler, J., 2004. Monopolistic pricing power for transgenic crops when technology adopters face irreversible benefits and costs. Applied Economics Letters 11, 969-973.

Weber, W.E., Bringezu, T., Broer, I., Eder, J., Holz, F., 2007. Coexistence between GM and non-GM maize crops - Tested in 2004 at the field scale level (Erprobungsanbau 2004). Journal of Agronomy and Crop Science 193(2), 79-92.

Weekes, R., Allnutt, T., Boffey, C., Morgan, S., Bilton, M., Daniels, R., Henry, C., 2007. A study of crop-to-crop gene flow using farm scale sites of fodder maize (Zea mays L.) in the UK. Transgenic Research 16, 203-211.

Wesseler, J., Scatasta, S., Nillesen, E., 2007. The Maximum Incremental Social Tolerable Irreversible Costs (MISTICs) and other benefits and costs of introducing transgenic maize in the EU-15. Pedobiologia 51, 261-269. 
${ }^{1}$ We observed that the standard errors of the outcomes were satisfactory low after 10 iterations (Table 1 and Table 2).

${ }^{2}$ We are indebted to Christian Tritten who proposed System $1 \mathrm{~b}$ as a potential solution. However, the HT farmer would still have to accept the yield loss on his non-HT pollen barrier owing to crop injury caused by drift of post-emergence herbicides from the HT system. We are grateful to Jeremy Sweet for pointing this out.

${ }^{3}$ The separate sale of contaminated non-GM crops to the GM outlet could be checked through an invoice after the transaction has taken place; no over-reporting of yields would be possible. However, the non-GM farmer has incentives to exaggerate the pollen barrier area. Moreover, price differences between IP and GM crops as compensation premiums are easily confounded with price discounts for small GM crop lots.

${ }^{4}$ Proprietary GM seed technologies are protected by intellectual property rights (i.e. patents) that confer monopoly rights to the discoverer - with some limitations. As a result, GM seed prices are higher than they would be in a perfectly competitive market, despite competition from chemical alternatives (Alexander et al., 2002; Lapan and Moschini, 2000; Weaver, 2004). If biotechnology companies set the GM seed price at a uniform, monopolistic level among a heterogeneous group of farmers, some farmers would find it profitable to adopt the innovation, while others would not (Demont et al., 2008a; Oehmke and Wolf, 2004; Weaver, 2004). Other reasons for incomplete adoption include farmers' uncertainty about anticipated GM gains (Weaver and Wesseler, 2004), and risk aversion towards new technologies, a well-known phenomenon in the literature on agricultural innovation (Feder et al., 1985; Sunding and Zilberman, 2001).

${ }^{5}$ We are grateful to an anonymous reviewer for pointing this out. 
Table 1: Mean and cumulative density of the shadow factors under a range of distance requirements and alternative planting scenarios

\begin{tabular}{|c|c|c|c|c|c|c|c|c|c|c|c|}
\hline Scenario & Distance requirement & $10 \mathrm{~m}$ & $20 \mathrm{~m}$ & $30 \mathrm{~m}$ & $40 \mathrm{~m}$ & $50 \mathrm{~m}$ & $60 \mathrm{~m}$ & $70 \mathrm{~m}$ & $80 \mathrm{~m}$ & $90 \mathrm{~m}$ & $100 \mathrm{~m}$ \\
\hline \multirow{3}{*}{$\begin{array}{l}13 \% \text { crop } \\
50 \% \text { GM }\end{array}$} & Mean shadow factor $\pm \mathrm{SE}$ & $0.01 \pm 0.00$ & $0.02 \pm 0.00$ & $0.03 \pm 0.00$ & $0.04 \pm 0.00$ & $0.06 \pm 0.00$ & $0.07 \pm 0.00$ & $0.09 \pm 0.00$ & $0.11 \pm 0.01$ & $0.12 \pm 0.01$ & $0.14 \pm 0.01$ \\
\hline & $F>1 / 3$ & $17 \%$ & $33 \%$ & $55 \%$ & $66 \%$ & $70 \%$ & $69 \%$ & $72 \%$ & $74 \%$ & $80 \%$ & $83 \%$ \\
\hline & $\%$ shadow with SF $>1$ & $3 \%$ & $17 \%$ & $27 \%$ & $36 \%$ & $45 \%$ & $51 \%$ & $56 \%$ & $56 \%$ & $59 \%$ & $63 \%$ \\
\hline \multirow{3}{*}{$\begin{array}{l}13 \% \text { crop } \\
25 \% \text { GM }\end{array}$} & Mea & $01 \pm 0$ & $04 \pm 0$ & $06 \pm 0$ & $08 \pm 0$ & $11 \pm 0$ & $13 \pm 0.01$ & $16 \pm 0.01$ & $18 \pm 0$ & $.22 \pm 0.02$ & $.27 \pm 0.03$ \\
\hline & $F>1 / 3$ & $29 \%$ & $53 \%$ & $60 \%$ & $61 \%$ & $68 \%$ & $72 \%$ & $74 \%$ & $75 \%$ & $77 \%$ & $83 \%$ \\
\hline & $\%$ shadow & $8 \%$ & $32 \%$ & $44 \%$ & $45 \%$ & $51 \%$ & $49 \%$ & $52 \%$ & $52 \%$ & $56 \%$ & $61 \%$ \\
\hline \multirow{3}{*}{$\begin{array}{l}13 \% \text { crop } \\
75 \% \text { GM }\end{array}$} & Mea & $00 \pm 0.00$ & $0.01 \pm 0.00$ & $02 \pm 0.00$ & $02 \pm 0.00$ & $0.03 \pm 0.00$ & $0.04 \pm 0.00$ & $0.05 \pm 0.00$ & $05 \pm 0.01$ & $06 \pm 0.01$ & $0.07 \pm 0.01$ \\
\hline & $\% \mathrm{sl}$ & $14 \%$ & $35 \%$ & $51 \%$ & $58 \%$ & $62 \%$ & $66 \%$ & $67 \%$ & $71 \%$ & $74 \%$ & $78 \%$ \\
\hline & $\%$ shadow & $0 \%$ & $14 \%$ & $28 \%$ & $37 \%$ & $44 \%$ & $43 \%$ & $46 \%$ & $49 \%$ & $52 \%$ & $52 \%$ \\
\hline \multirow{3}{*}{$\begin{array}{l}6 \% \text { crop } \\
50 \% \text { GM }\end{array}$} & Mean shado & $0.00 \pm 0.00$ & $0.01 \pm 0.00$ & $0.02 \pm 0.00$ & $0.03 \pm 0.00$ & $0.03 \pm 0.01$ & $0.04 \pm 0.01$ & $0.05 \pm 0.01$ & $0.06 \pm 0.01$ & $0.07 \pm 0.01$ & $0.08 \pm 0.0$ \\
\hline & $\% \mathrm{sl}$ & $24 \%$ & $54 \%$ & $59 \%$ & $68 \%$ & $69 \%$ & $68 \%$ & $74 \%$ & $75 \%$ & $73 \%$ & $76 \%$ \\
\hline & $\%$ sha & $0 \%$ & $21 \%$ & $35 \%$ & $48 \%$ & $49 \%$ & $54 \%$ & $53 \%$ & $56 \%$ & $55 \%$ & $54 \%$ \\
\hline \multirow{3}{*}{$\begin{array}{l}26 \% \text { crop } \\
50 \% \text { GM }\end{array}$} & ladow factor \pm SE & $0.02 \pm 0.00$ & $0.05 \pm 0.00$ & $0.08 \pm 0.01$ & $0.11 \pm 0.01$ & $0.15 \pm 0.01$ & $0.18 \pm 0.01$ & $0.22 \pm 0.02$ & $0.26 \pm 0.02$ & $0.30 \pm 0.02$ & $0.34 \pm 0.02$ \\
\hline & $\%$ sh & $24 \%$ & $47 \%$ & $58 \%$ & $66 \%$ & $72 \%$ & $76 \%$ & $78 \%$ & $80 \%$ & $81 \%$ & $83 \%$ \\
\hline & $\%$ shadow with SF > 1 & $7 \%$ & $25 \%$ & $36 \%$ & $45 \%$ & $51 \%$ & $53 \%$ & $55 \%$ & $59 \%$ & $64 \%$ & $65 \%$ \\
\hline
\end{tabular}

Notes: All estimates are averages, based on 10 random allocations of GM and non-GM crop fields. The shadow factor is the ratio of the shadow area to the remaining GM area. $\mathrm{SF}=$ shadow factor; $\mathrm{SE}=$ standard error

Source: Authors' calculations based on GIS dataset of the sample square (Pessel et al., 2001). 
Table 2: Mean shadow factors induced by complying with rigid isolation distances of $50 \mathrm{~m}$ under alternative planting scenarios in the extreme case of total field conversion

\begin{tabular}{|c|c|c|c|c|c|c|c|}
\hline Scenario & Phase & Crop area (ha) & GM area (ha) & Adoption & Shadow fields & Shadow area (ha) & Shadow factor \pm SE \\
\hline \multirow{5}{*}{$\begin{array}{l}13 \% \text { crop } \\
50 \% \text { GM }\end{array}$} & Phase 1 & 559 & 280 & $50 \%$ & 29 & 81 & $0.42 \pm 0.05$ \\
\hline & Phase 2 & 559 & 199 & $36 \%$ & 32 & 90 & $0.49 \pm 0.06$ \\
\hline & Phase 3 & 559 & 190 & $34 \%$ & 33 & 91 & $0.50 \pm 0.05$ \\
\hline & Phase 4 & 559 & 189 & $34 \%$ & 33 & 91 & $0.50 \pm 0.05$ \\
\hline & Domino-effect & & $-33 \%$ & $-16 \%$ & $+14 \%$ & $+16 \%$ & $+23 \% \pm 29 \%$ \\
\hline \multirow{5}{*}{$\begin{array}{l}13 \% \text { crop } \\
25 \% \text { GM }\end{array}$} & Phase 1 & 547 & 137 & $25 \%$ & 23 & 67 & $1.08 \pm 0.18$ \\
\hline & Phase 2 & 547 & 70 & $13 \%$ & 25 & 70 & $1.17 \pm 0.19$ \\
\hline & Phase 3 & 547 & 67 & $12 \%$ & 25 & 71 & $1.19 \pm 0.18$ \\
\hline & Phase 4 & 547 & 66 & $12 \%$ & 25 & 71 & $1.20 \pm 0.18$ \\
\hline & Domino-effect & & $-52 \%$ & $-13 \%$ & $+7 \%$ & $+9 \%$ & $+17 \% \pm 24 \%$ \\
\hline \multirow{5}{*}{$\begin{array}{l}13 \% \text { crop } \\
75 \% \text { GM }\end{array}$} & Phase 1 & 546 & 410 & $75 \%$ & 22 & 77 & $0.25 \pm 0.05$ \\
\hline & Phase 2 & 546 & 333 & $61 \%$ & 28 & 102 & $0.36 \pm 0.08$ \\
\hline & Phase 3 & 546 & 308 & $56 \%$ & 30 & 106 & $0.39 \pm 0.08$ \\
\hline & Phase 4 & 546 & 303 & $55 \%$ & 30 & 106 & $0.39 \pm 0.08$ \\
\hline & Domino-effect & & $-26 \%$ & $-19 \%$ & $+36 \%$ & $+41 \%$ & $+57 \% \pm 46 \%$ \\
\hline \multirow{5}{*}{$\begin{array}{l}6 \% \text { crop } \\
50 \% \text { GM }\end{array}$} & Phase 1 & 262 & 131 & $50 \%$ & 9 & 24 & $0.23 \pm 0.05$ \\
\hline & Phase 2 & 262 & 107 & $41 \%$ & 9 & 24 & $0.24 \pm 0.05$ \\
\hline & Phase 3 & 262 & 107 & $41 \%$ & 9 & 24 & $0.24 \pm 0.05$ \\
\hline & Phase 4 & 262 & 107 & $41 \%$ & 9 & 24 & $0.24 \pm 0.05$ \\
\hline & Domino-effect & & $-19 \%$ & $-9 \%$ & $+3 \%$ & $+2 \%$ & $+3 \% \pm 8 \%$ \\
\hline \multirow{5}{*}{$\begin{array}{l}26 \% \text { crop } \\
50 \% \text { GM }\end{array}$} & Phase 1 & 1,097 & 548 & $50 \%$ & 90 & 310 & $1.37 \pm 0.13$ \\
\hline & Phase 2 & 1,097 & 238 & $22 \%$ & 105 & 357 & $1.98 \pm 0.18$ \\
\hline & Phase 3 & 1,097 & 191 & $17 \%$ & 107 & 362 & $2.04 \pm 0.18$ \\
\hline & Phase 4 & 1,097 & 186 & $17 \%$ & 108 & 362 & $2.05 \pm 0.17$ \\
\hline & Domino-effect & & $-66 \%$ & $-33 \%$ & $+20 \%$ & $+18 \%$ & $+52 \% \pm 15 \%$ \\
\hline
\end{tabular}

Notes: All estimates are averages, based on 10 random allocations of GM and non-GM crop fields. Differences in average crop areas among scenarios with equal plantings are due to the precision of the constrained randomization procedure which has been set at the level of the planting density at $1 \%$. The domino-effect expresses the relative difference in per cent between the cumulative value in Phase 4 and the value in Phase 1 . The shadow factor is the ratio of the shadow area to the remaining GM area. SE = standard error

Source: Authors' calculations based on GIS dataset of the sample square (Pessel et al., 2001). 


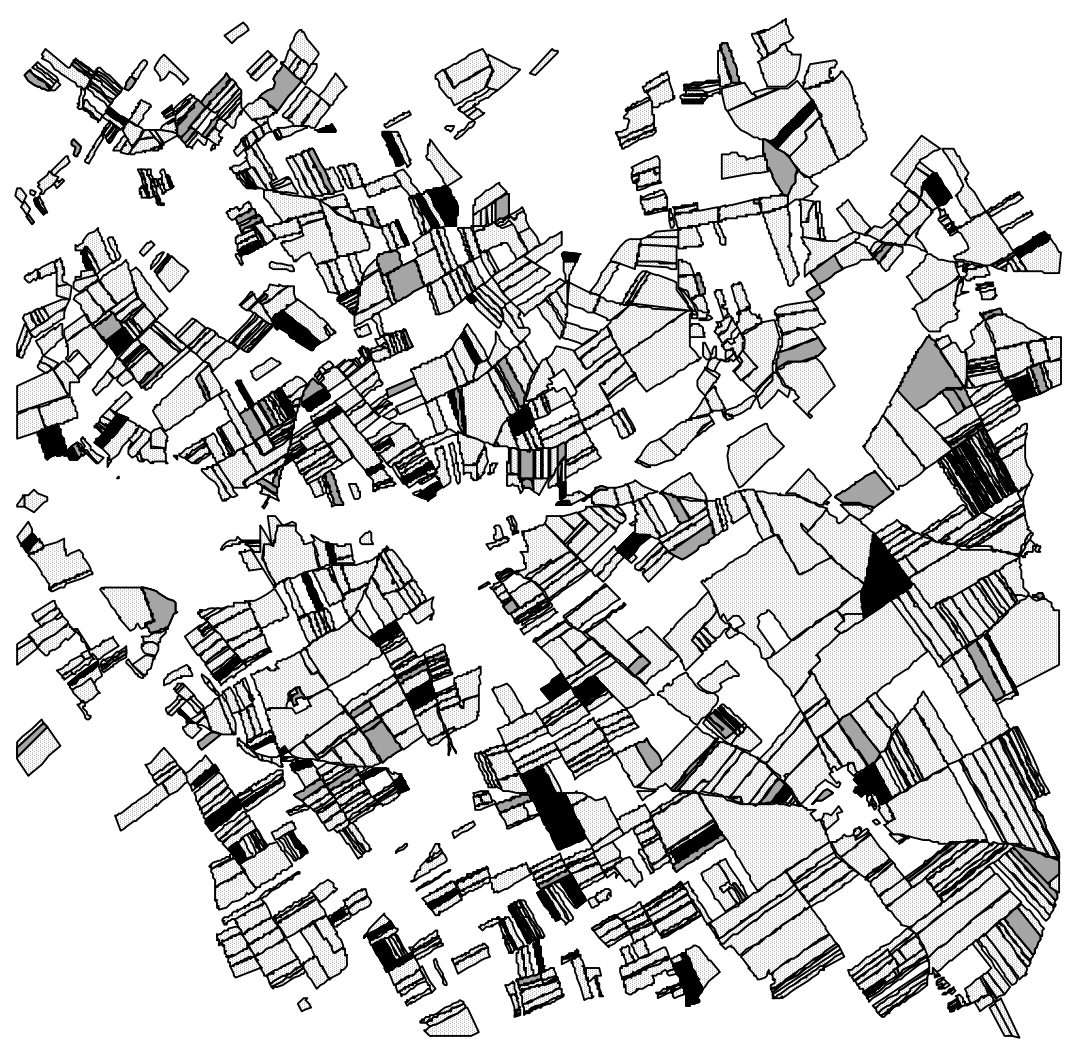

Figure 1: GIS shapefile of the sample square in Selommes (Loir-et-Cher)

Notes: The figure represents a random draw of the benchmark scenario (crop planting density of $13 \%$ and GM adoption rate of 50\%). Arable fields are dotted, non-GM crop fields grey and GM crop fields black. Source: Authors' simulation based on GIS dataset of the sample square (Pessel et al., 2001). 


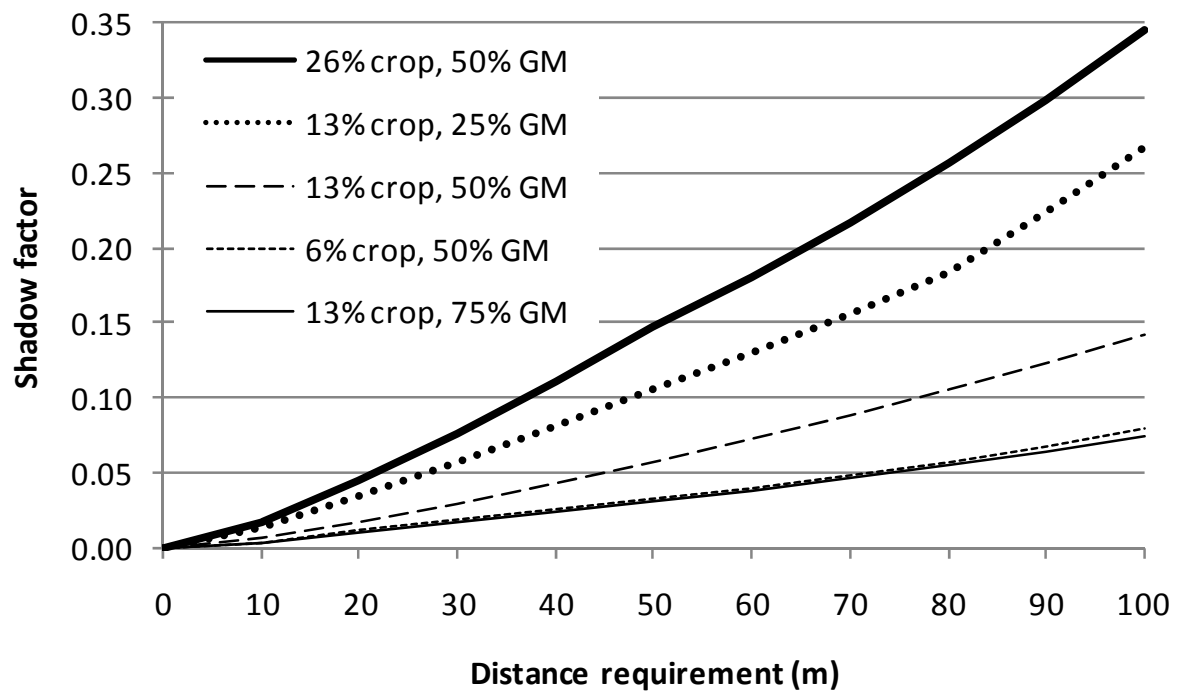

Figure 2: Evolution of mean shadow factors under a range of distance requirements and alternative planting scenarios

Notes: All estimates are averages, based on 10 random allocations of GM and non-GM crop fields. The shadow factor is the ratio of the shadow area to the remaining GM area.

Source: Authors' calculations based on GIS dataset of the sample square (Pessel et al., 2001). 


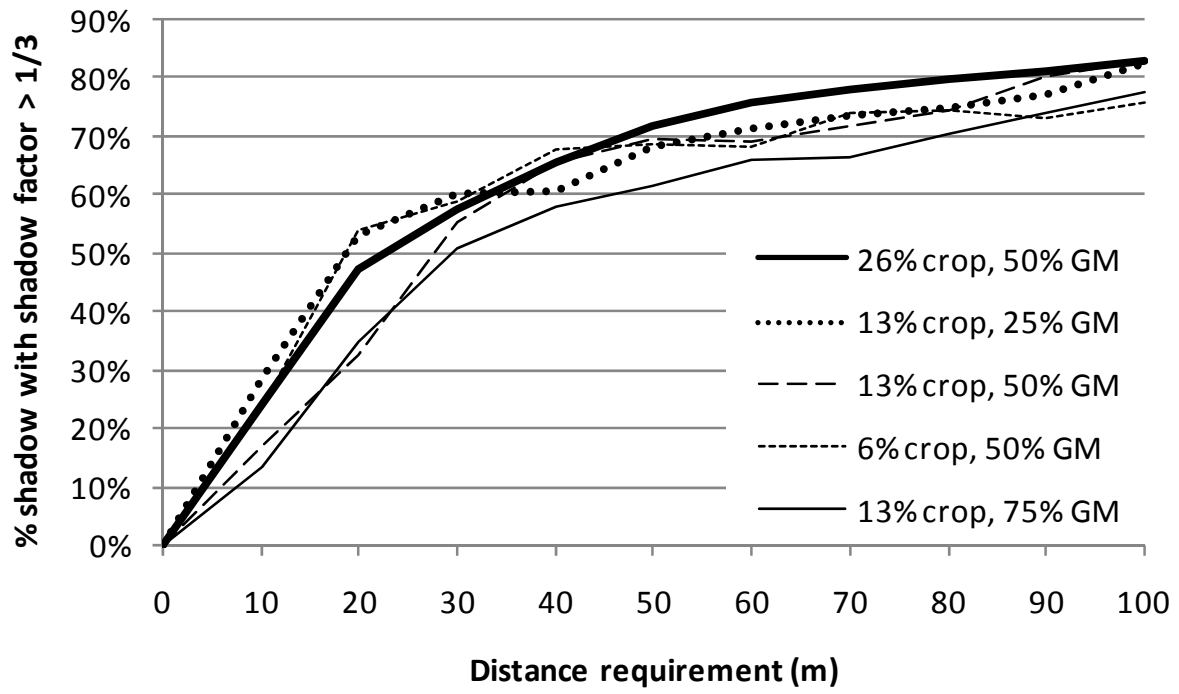

Figure 3: Evolution of the cumulative density of shadow factors greater than one third on the shadow area under a range of distance requirements and alternative planting scenarios

Notes: All estimates are averages, based on 10 random allocations of GM and non-GM crop fields. The shadow factor is the ratio of the shadow area to the remaining GM area.

Source: Authors' calculations based on GIS dataset of the sample square (Pessel et al., 2001). 


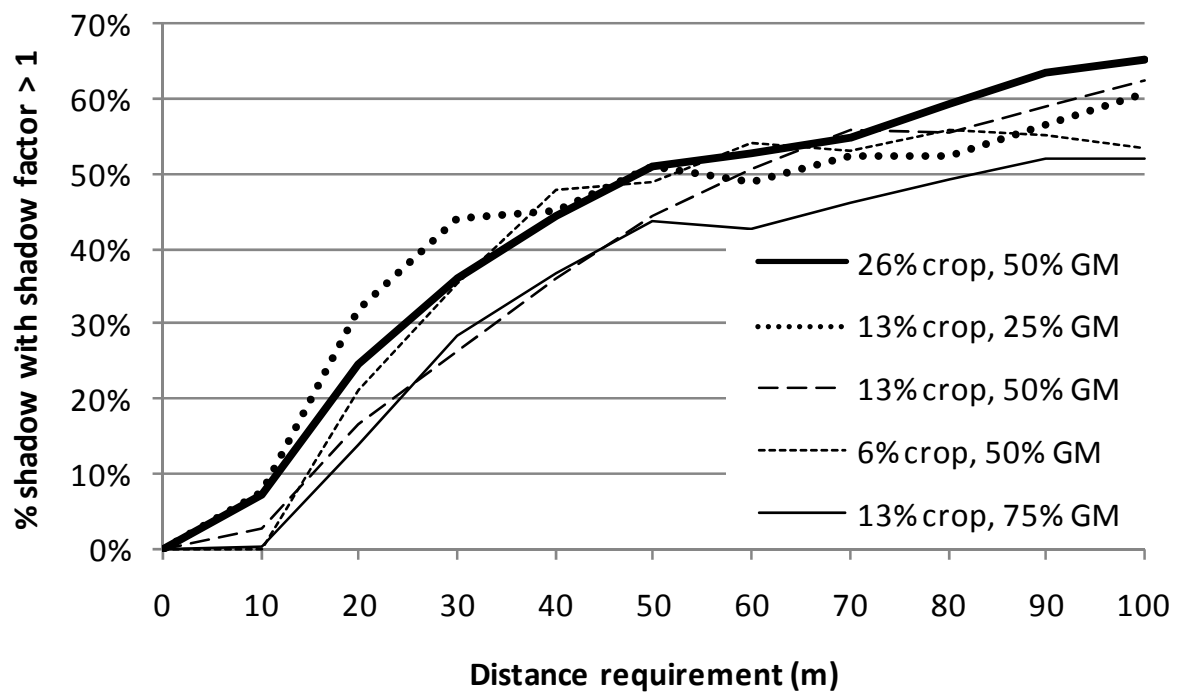

Figure 4: Evolution of the cumulative density of shadow factors greater than one on the shadow area under a range of distance requirements and alternative planting scenarios Notes: All estimates are averages, based on 10 random allocations of GM and non-GM crop fields. The shadow factor is the ratio of the shadow area to the remaining GM area.

Source: Authors' calculations based on GIS dataset of the sample square (Pessel et al., 2001). 